\title{
Educação étnico-racial: desafios cotidianos para além dos aspectos legais
}

\author{
Elison Antonio Paim ${ }^{1}$ \\ Universidade Federal de Santa Catarina, Professor Organizador da Seção Temática
}

\begin{abstract}
Gentem, essas feridas todas eu carreguei na pele, na alma e trago comigo até hoje as cicatrizes. Eu e a maioria do povo negro brasileiro. Feridas que ainda não se curaram e todo santo dia são cutucadas para mantê-las abertas, sangrando, como uma forma de demonstrar que lugar de preto é na Senzala, nessa Senzala moderna, disfarçada, à espreita, como se vigiasse o nosso povo. Povo aliás, que descende em sua maioria dos negros que colonizaram e construíram o nosso país.

Hoje li sobre mais uma "cutucada" dessas na ferida aberta do Brasil Colônia. Nem faço juizo de valor sobre quem errou ou se teve intenção ou não de errar. Faço um alertal Quer ser elegante? Então pense no quanto pode machucar o próximo, sua memória, os flagelos do seu povo e suas origens, ao escolher um tema para celebrar uma festa ou "enfeitar" um momento feliz de sua vida. (SOARES, 2019, p. 1).
\end{abstract}

Essas palavras da cantora brasileira Elza Soares comentam a polêmica festa de aniversário oferecida pela diretora da revista Vogue, Donata Meireles, cuja temática foi o Brasil colonial, em que as recepcionistas negras estavam vestidas de mucamas e a aniversariante, de sinhá com direito a trono e tudo mais. Esse episódio nos remete à grande ferida da nação brasileira - o racismo e o preconceito para com pessoas negras e indígenas - que muitos teimam em negar sua existência tentando o tempo todo reafirmar que o Brasil é uma verdadeira democracia racial e que deve ser exemplo para o mundo.

Essa falácia da democracia racial é cotidianamente desmascarada. Todos os dias inúmeros jovens negros são assassinados; nas universidades reafirma-se diuturnamente que não há necessidade de existirem políticas de cotas raciais; os negros e indígenas são invisibilizados na história escolar; lhes é negado o direito de ter sua cultura e história ensinadas, mesmo em escolas localizadas em terras indígenas ou quilombolas. Nesse sentido, os currículos escolares em todos os níveis de ensino continuam a negar/silenciar sistematicamente a existência de outras histórias para além daquela dos reis europeus, enfim são numerosos os exemplos que poderiam ser apresentados.

Após mais de 500 anos de lutas pelo direito ao ensino da cultura e história dos povos de origem africana e dos povos indígenas tivemos grandes avanços legais com a conquista, aprovação e implementação da Lei n. 10.639/2003 e, posteriormente, da Lei n. 
11.645/2008, que tornaram obrigatórios o ensino da cultura e história desses inúmeros povos. No entanto, passados 15 anos da primeira Lei e 10 anos da segunda, os avanços ainda são mínimos no sentido de que as escolas e universidades efetivamente assumam a necessidade de dispor em seus currículos a cultura dos povos afrodescendentes e indígenas.

Ainda percebemos a discriminação e o preconceito arraigados nos currículos. Estes continuam focados em perspectivas racistas, colonialistas, sexistas, eurocêntricas e epistemicidas. Mas, afinal, por que os currículos centrados nessas características se mantêm em ação em pleno século XXl?

A seguir apresento um breve diálogo com perspectivas históricas e contemporâneas de cunho intercultural e decolonial sobre raça e racismo que permeiam e definem formas de viver e ser nas sociedades, especialmente aquelas africanas e americanas, colonizadas pelos europeus. Inicialmente, aponto algumas análises que procuram caracterizar a construção e implementação de perspectivas racistas e eurocêntricas que deram suporte à colonialidade implantada nos continentes não europeus. Poderíamos nos perguntar, ainda, por que trabalhar conceitualmente com a categoria raça ou defender a necessidade do trabalho com culturas de matriz africana e indígenas? De maneira direta podemos afirmar que educar para as relações étnico-raciais "Representa reelaborar e ressignificar uma categoria produzida no contexto da colonização nos termos e na visão daqueles cujos ancestrais foram escravizados." (GOMES, 2018, p. 243).

Para além da obrigatoriedade legal de trabalhar com culturas que historicamente foram silenciadas precisamos compreender que a colonialidade estabeleceu o racismo como um dos princípios estruturantes e organizadores da dominação na modernidade capitalista. Assim,

\footnotetext{
desde a divisão internacional do trabalho até as hierarquias epistêmicas, sexuais, de gênero, religiosas, pedagógicas, médicas, junto com as identidades, subjetividades, de tal maneira que divide tudo entre as formas e os seres superiores (civilizados, hiper-humanizados, etc., acima da linha do humano) e outras formas e seres inferiores (selvagens, bárbaros, desumanizados, etc., abaixo da linha do humano). (GROSFOGUEL, 2018, p. 59).
}

Na mesma esteira de pensamento - decolonial - Mignolo (2014a, p. 48) defende que o eurocentrismo "se constituyó en el centro de todas las esferas de la vida social: política, económica, religiosa, epistemológica, estética, lingüística, subjetiva (género, rasa, sexualidad)", para que tal pensamento e práticas pudessem se firmar como dominação e controle dos europeus sobre os demais povos. 0 racismo construído pautado na premissa de que "ciertos cuerpos eran inferiores que otros, y que los cuerpos inferiores llevaban inteligencia inferior." (MIGNOLO, 2014a, p. 185). 
Para a efetivação do domínio europeu sobre africanos e indígenas, na colonização foram utilizadas diferentes formas de violências e violações tanto de corpos quanto de mentes. 0s saberes, culturas, religiões, sexualidades, economias, etc. foram considerados não conhecimentos, portanto, não válidos, não reconheciveis enquanto tal. Assassinatos, violações múltiplas foram gradualmente legitimadas e entendidas como normais e óbvias dentro da legitimidade legal e moral da escravização e racismo. Dessa forma, "negros, indígenas, y otros sujetos 'de color', son los que sufren de forma preferencial los actos viciosos del sistema." (MALDONADO-TORRES, 2007, p. 149).

Como complemento do racismo pautado em fenótipos de indígenas e africanos constituiu-se também o que vem sendo denominado de racismo epistêmico. Este constitui-se como a face complementar do eurocentrismo. Ao negar ou desqualificar os conhecimentos e saberes dos demais povos algumas categorias marcam a "superioridade" europeia. São utilizadas "desarrollo; progreso; productividad; neutralidad; relación desigual, desarraigada y distanciada de un sujeto que observa y administra un 'objeto' - naturaliza reducida a cosa y epistemológicamente objetivada; antropocentrismo en lugar de cosmocentrismo" (SEGATO, 2014, p. 49). Em momento posterior no mesmo texto Segato (2014, p. 54) advoga que "el racismo es epistémico, em el sentido de que las epistemes de los conquistados y colonizados son discriminadas negativamente. Racismo es eurocentrismo porque discrimina saberes y populaciones, reduce civilizaciones, valores capacidades, creaciones e creencias."

Autores como Walter Mignolo (2003, 2010, 2014a, 2014b, 2014c), Catherine Walsh (2006, 2007, 2008, 2009a, 2009b, 2013, 2017), Anibal Quijano (2009, 2014), Ramón Grosfoguel (2009, 2018), Henrique Dussel (2005, 2009, 2016), Edgard Lander (2005), Santiago Castro-Gomez (2005, 2007) e Walter Mignolo, Catherine Walsh e Álvaro Garcia Linera (2014) afirmam que a colonialidade implementada pelos europeus para com os povos africanos e americanos se traduziu na forma de colonialidade do poder, colonialidade do ser, colonialidade da natureza e especialmente a colonialidade do saber.

Assim, uma das formas muito utilizada para o domínio - controle dos saberes, dos seres, dos poderes e das naturezas - é apresentada de modo muito contundente na educação em seus diferentes níveis. Especialmente quando em seus currículos pratica de maneira deliberada o silenciamento das memórias e histórias dos povos de matriz africana, indígena e outras não europeias. Como materialização dessas práticas de silenciamento os "estudantes devem lidar com problemas de racismo e que, no currículo, não encontram refletidas as histórias, os idiomas, os conhecimentos e os modos de aprendizagem próprios de seus povos ao que se soma o fato de se encontrarem muito distantes de suas famílias e comunidades." (MAT0, 2016, p. 49). Em complementariedade às ideias de Daniel Mato, a pedagoga brasileira Nilma Lino Gomes afirma que a colonialidade e os racismos se enraizam e traduzem nos currículos quando 
disponibilizamos aos discentes leituras coloniais do mundo, autores que, na sua época defendiam pensamentos autoritários, racistas, xenófobos e que produziram teorias sem fazer a devida contextualização e a crítica sobre quem foram, pelo que lutaram, suas contradições, suas contribuições e seus limites. E sem mostrar o quanto a sociedade, a cultura, a política e a educação repensaram e questionaram várias "verdades" aprendidas há tempos atrás e como isso possibilitou e tem possibilitado a garantia de direitos antes negados. (GOMES, 2018, p. 232).

A pensadora estadunidense naturalizada equatoriana Katherine Walsh, referindose aos povos indígenas do Equador, com os quais tem sistematicamente trabalhado, insiste que o currículo eurocêntrico quando inclui temáticas da história e cultura dos povos indígenas - podemos estender para os africanos - o faz sem um

\footnotetext{
dialogo crítico con el conocimiento y las formas de conocimiento típicamente asociadas al mundo occidental. En este proceso, el conocimiento y el pensamiento indigena no se encontran reificados sino que sierven como base desde donde "dialogar con", revertendo la histórica subalternizacion y proponiendo una incorporación diferente. (WALSH, 2007, p. 58).
}

Em uma tentativa, pequena por certo, de decolonizar currículos implementando uma educação outra que seja antirracista propusemos esta seção temática na tentativa de apresentação de experiências significativas que vêm sendo desenvolvidas em diversos países e particularmente no Brasil. Os artigos que ora apresentamos debatem as questões étnicoraciais a partir de diferentes locais como as universidades de Cauca, na Colômbia, University of KwaZulu-Natal, na África do Sul, as universidades federais do Rio Grande do Sul, de Santa Catarina, Sergipe, Universidade de Passo Fundo e Universidade Tiradentes. São resultados de pesquisas de mestrado, doutorado, pós-doutorado que expressam conhecimentos de áreas como Pedagogia, História, Geografia, Literatura, Sociologia, Biologia e Teologia.

0 artigo Políticas públicas de educación afrocolombiana: el arte de escamotear el derecho de los pueblos, de Jorge Enrique García Rincón (Professor doutor da Universidad de Cauca - Colômbia), descreve os momentos em que o Estado colombiano legislou para as populações de ascendência africana no tocante aos direitos educativos. Mostra os aspectos contraditórios das leis específicas para as comunidades, as quais foram naturalizadas em um duplo jogo de inclusão-negação, em que os direitos dos negros foram normatizados, porém não são aplicados na prática. Dessa forma, a inclusão das comunidades afrodescendentes às políticas educativas do Estado corresponde a uma estratégia de desmobilização. 0 autor destaca a visão colonial e racista que marca as elites colombianas, mas em contraposição há também a emergência de grupos de intelectuais negros que conseguiram influenciar de maneira significativa os processos 
de reivindicação de uma educação destinada a revitalizar as construções sociais, políticas e culturais dos afrocolombianos. Essas reivindicações desembocam em uma perspectiva de abertura à diversidade cultural expressa na Constituição de 1991, cuja perspectiva se evidencia como estratégia de uma forma de multiculturalismo, o estatal.

Em Education and contemporary issues in South Africa: a look from the high education crisis, Felipe Gustavo Koch Buttelli (Pós-doutorando na University of KwaZulu-Natal na África do Sul) e Clint Le Bruyns (Professor doutor da University of KwaZulu-Natal na África do Sul) apresentam aspectos históricos e uma conceitualização da situação socioeconômica contemporânea da África do Sul. A reflexão teórica desse artigo articula a participação de ambos os autores no movimento da juventude, Taxas Deverão Cair (Fees Must Fall. Apresentam como aumentou o movimento de estudantes exigindo educação gratuita e uma reforma decolonial do currículo do ensino superior, tanto quanto a justiça de gênero e racial. 0 movimento Fees Must Fall conduziu à, mas também protestou contra a militarização do campi, a prisão de estudantes, a depredação, o incêndio criminoso e a violência dos diferentes lados.

A Educação das relações étnico-raciais no Brasil: paradoxos e obstáculos, artigo de Telmo Marcon (Professor Titular I, vinculado ao Programa de Pós-graduação em Educação da Universidade de Passo Fundo) e Ivan Penteado Dourado (Doutor em Educação pela Universidade de Passo Fundo) trata da educação das relações étnico-raciais do ponto de vista social e das políticas educacionais. 0 enfoque dado destaca elementos que se constituem em precondição para avançar no debate sobre o tema em instituições educativas. Os autores fundamentam-se na tese da persistência na sociedade brasileira de inúmeros preconceitos sociais e étnico-culturais que obstaculizam o debate transparente e democrático. No texto, destacam-se os paradoxos que perpassam a formação sociocultural, política, algumas formas de reprodução de preconceitos raciais e alguns obstáculos que dificultam o diálogo e a democratização efetiva da sociedade brasileira.

Os autores Carla Beatriz Meinerz (Professora da Universidade Federal do Rio Grande do Sul vinculada ao Programa de Pós-Graduação em Educação) e Cássio Michel dos Santos Camargo (Doutorando em Educação pela UFRGS e Professor de História no Ensino Médio), no artigo Reconhecimentos, sensibilidades e relações étnico-raciais: a obrigatoriedade do ensino do Holocausto em Porto Alegre, convocam-nos a refletir sobre as memórias ressentidas em luta por reconhecimento e os temas sensíveis nas prescrições legais acerca do que deva ser ensinado nas aulas de História da Educação Básica no Brasil. 0 foco é a aprovação pela Câmara Municipal de Porto Alegre da Lei n. 10.965/2010, que torna obrigatório o ensino do Holocausto nas escolas da rede municipal de ensino. Na análise, destaca-se a historização das políticas afirmativas que atingem os currículos de História, dentro e fora do Brasil, relacionando-as com os projetos de educação das relações étnico-raciais e de educação para os direitos humanos. 
No artigo $A$ educação das relações raciais no currículo: as licenciaturas em Geografia em Santa Catarina, Joana Célia dos Passos (Professora no Programa de PósGraduação em Educação e no Programa de Pós-Graduação Interdisciplinar de Ciências Humanas da Universidade Federal de Santa Catarina) e Azânia Mahin Romão Nogueira (Mestre em Geografia pela Universidade Federal de Santa Catarina) destacam como a Geografia enquanto campo de conhecimento contribui para o empoderamento dos sujeitos para a construção de sua identidade e de seu posicionamento e atuação no mundo. As autoras apontam como essencial o debate sobre as relações raciais para a percepção da necessidade de mudanças estruturais na sociedade brasileira e para a compreensão da segregação urbana, do direito à terra e das dinâmicas sociais e econômicas da população. Considerando esses aspectos, o artigo analisa os currículos de cursos de Licenciatura em Geografia de cinco Instituições de Ensino Superior localizadas no Estado de Santa Catarina, procurando perceber de que maneira se apresentam as questões raciais nesses cursos. Ao analisar os textos legais que normatizam a formação de professores no Brasil, bem como da Geografia e os que interpretam e complementam a Lei n. 10.639/03 nos documentos, evidencia-se que, embora a legislação atual e suas normativas curriculares tenham assimilado no corpo de seus textos as questões raciais como estruturantes e princípios educacionais, a presença de conhecimentos e a discussão sobre estas ainda é tímida nesses cursos, que estão, em sua maioria, cumprindo o mínimo exigido pela Lei.

Em Desfazendo imagens, construindo identidades: decolonizando os processos formativos de educadorxs, de Josiane Beloni de Paula (Doutoranda em Educação pela Universidade Federal de Santa Catarina), Patrícia Magalhães Pinheiro (Doutoranda em Educação pela Universidade Federal de Santa Catarina) e Elison Antonio Paim (Professor Adjunto IV do Departamento de Metodologia de Ensino da Universidade Federal de Santa Catarina vinculado ao Programa de Pós-Graduação em Educação e ao Programa de Mestrado Profissional em Ensino de História - Profhistória), os autores dialogam com memórias e experiências de educadorxs que desenvolvem práticas de resistência em sala de aula no que tange à valoração da presença negra e indígena na sociedade brasileira. A ênfase é naquelas práticas que pretendem criar caminhos e brechas para a reversão de uma ordem opressora, desenraizando, assim, preconceitos impregnados no imaginário social moderno/colonia//colonialista. Ao dialogar com autorxs decoloniais evidenciam a importância da escola como agente de luta contra a opressão, a desvalorização de saberes e de formas outras de ser e estar no mundo.

No artigo 0 projeto assimilacionista português: o Diretório Pombalino sob um olhar decolonial, Valéria Maria Santana Oliveira (Doutora em Educação pela Universidade Tiradentes e Professora da mesma instituição) e llka Miglio de Mesquita (Professora da Universidade Tiradentes-SE vinculada ao Programa de Pós-Graduação em Educação) abordam como a educação escolar indígena no Brasil vem sendo apresentada desde o período colonial, como têm sido criadas, revogadas e recriadas diversas leis que versam sobre os direitos dos 
indígenas. Analisam desdobramentos da legislação indigenista criada pelo Marquês de Pombal: - Diretório dos índios, de 1755, e o Alvará de 1758, dispositivos legais que impõem a língua portuguesa nos trabalhos pedagógicos e de catequese indígena. Com essa legislação foi imposta a cosmovisão do colonizador resultando em uma política de assimilacionismo que contribuiu para a hibridação cultural de diversos povos indígenas.

Marizete Lucini (Professora da Universidade Federal de Sergipe vinculada ao Programa de Pós-Graduação em Educação e ao Programa de Mestrado Profissional em Ensino de História - Profhistória) e Leyla Menezes de Santana (Doutoranda em Educação pela Universidade Federal de Sergipe), no artigo Pedagogia decolonial e educação de jovens, adultos e idosos no contexto de uma sociedade racializada, objetivam apresentar reflexões assentadas no âmbito da pedagogia decolonial como contribuições insurgentes às práticas pedagógicas da educação de jovens, adultos e idosos (EJA). 0 caminho percorre os tensionamentos experimentados pela EJA com relação às suas formas colonizadoras, em uma sociedade marcadamente racializada. Ao mesmo tempo, estabelecem relações com as práticas pedagógicas experienciadas por alfabetizadoras populares.

0 artigo Personagens negras nos livros de imagens do Programa Nacional Biblioteca da Escola (PNBE) para a Educação Infantil, de Maria Laura Pozzobon Spengler (Doutora em Educação pela Universidade Federal de Santa Catarina) e Eliane Santana Dias Debus (Professora do Departamento de Metodologia de Ensino da Universidade Federal de Santa Catarina vinculada ao Programa de Pós-Graduação em Educação), busca evidenciar as personagens negras nos livros de imagem do acervo do Programa Nacional Biblioteca da Escola (PNBE) para a Educação Infantil. As autoras mapearam 77 títulos divulgados pelo Ministério da Educação/Centro de Alfabetização Leitura e Escrita (MEC/CEALE) dos quais foram analisados 13 títulos, sendo que cinco trazem personagens sem participação ativa, e oito trazem personagens negras que participam da narrativa. A análise busca evidenciar qual a representação proposta por essas narrativas e suas contribuições, ou não, para a Educação das Relações Étnico-Raciais (ERER).

A seção temática dossiê é composta, ainda, pela resenha Contando outra história da educação popular: uma interlocução entre o pensamento de Paulo Freire e Orlando Fals Borda produzida por Sil-Lena Ribeiro Calderaro Oliveira (Mestre em Educação pela Universidade Federal de Santa Catarina e Professora na Educação Básica da Rede estadual do Pará) e Elison Antonio Paim (Professor Adjunto IV do Departamento de Metodologia de Ensino da Universidade Federal de Santa Catarina vinculado ao Programa de Pós-Graduação em Educação e ao Programa de Mestrado Profissional em Ensino de História - Profhistória) a partir da leitura do livro Por uma pedagogia decolonial na América Latina: reflexões em torno do pensamento de Paulo Freire e Orlando Fals Borda, de autoria do Professor João Colares da Mota Neto. Em seu livro, originário de sua tese de doutorado, o professor evidencia como 
o sistema colonial implementado nas Américas foi sendo estruturado para que os europeus se apoderassem das terras e da natureza nas dimensões animal, vegetal e principalmente mineral e encarcerassem tanto os corpos quanto as mentes. Tudo foi organizado para a total submissão e exploração. Porém, os mais de 500 anos de exploração e controle também geraram inúmeras resistências. Nesse sentido, foi estabelecido um diálogo com o pensamento de Freire e Fals Borda, destacando-se suas contribuições para outras formas de educar.

Para finalizar as contribuições e reflexões da seção temática, Elison Antonio Paim (Professor Adjunto IV do Departamento de Metodologia de Ensino da Universidade Federal de Santa Catarina vinculado ao Programa de Pós-Graduação em Educação e ao Programa de Mestrado Profissional em Ensino de História - Profhistória) e Pedro Mülbersted Pereira (Doutorando em Educação pela Universidade Federal de Santa Catarina) trazem a público Uma experiência com educação intercultural indígena: entrevista com a professora Joziléia Daniza Jagso Inácio Schild Kaingang. Entre outras temáticas a narradora destaca a educação intercultural e específica desenvolvida em escolas do povo Kaingang do qual é integrante. Destaca-se, ainda, a formação de professores indígenas no curso de Licenciatura Intercultural do Sul da Mata Atlântica oferecido pela Universidade Federal de Santa Catarina no qual a professora é uma das coordenadoras.

Mais do que nunca, faz-se necessário pesquisar, debater, ensinar, problematizar em nossas escolas, nas universidades, nas ruas, igrejas, seja lá onde for, as temáticas relativas aos povos afrodescendentes e indígenas. Pois "só é possível decolonizar os currículos e o conhecimento se descolonizarmos o olhar sobre os sujeitos, suas experiências, seus conhecimentos e forma como os produzem." (GOMES, 2018, p. 235). Para tanto, não basta a existência de leis antirracistas e parâmetros educacionais voltados à necessidade de Educação para as relações étnico-raciais (ERER) se não houver vontade política de cada professor, diretor ou dirigentes governamentais no combate a toda forma de discriminação, silenciamento e apagamento de memórias.

A expectativa é que esta seção temática contribua de alguma forma para a construção, em múltiplos espaços, de relações de efetivo respeito aos diferentes sujeitos independentemente de sua cor.

Desejo a todxs boas leituras!

\section{REFERÊNCIAS}

CASTRO-GÓMEZ, S.; GROSOFOGUEL, R. (ed.). El giro decolonial: reflexiones para una diversidad epistémica más allá del capitalismo global. Bogotá: Siglo del Hombre Editores: Universidad Javeriana, Instituto Pensar, 2007. 
CASTR0-GÓMEZ, S. La Hybris del Punto Cero: ciencia, raza e ilustración en la Nueva Granada (17501816). Bogotá: Editorial Pontificia Universidad Javeriana, 2005.

DUSSEL, E. Europa, modernidade e eurocentrismo. In: LANDER, E. (org.) Colonialidade do saber: eurocentrismo e ciências sociais. Perspectivas da América Latina. Buenos Aires: CLACSO, 2005. p. 24-32.

DUSSEL, E. Mediações anti-cartesianas sobre a origem do anti-discurso filosófico da modernidade. In: SANTOS, B. de Souza; MENESES, M. P. (org.). Epistemologias do Sul. Coimbra: Almedina, 2009.

DUSSEL, E. Transmodernidade e interculturalidade: interpretação a partir da filosofia da libertação. Revista Sociedade e Estado, v. 31, n. 1, p. 51-73, jan./abr. 2016.

GOMES, N. L. 0 Movimento Negro e a intelectualidade negra descolonizando os currículos. In: BERNARDINO-COSTA, J.; MALDONADO-TORRES, N.; GROSFOGUEL, R. (org.). Decolonialidade e pensamento afrodiáspórico. Belo Horizonte: Autêntica Editora, 2018. p. 223-246. (Coleção cultura negra e identidade).

GROSFOGUEL, R. Para descolonizar os estudos da economia política e os estudos pós-coloniais: transmodernidade, pensamento de fronteira e colonialidade global. In: SANTOS, B. de S.; MENESES, M. P. (org.). Epistemologias do Sul. Coimbra: Almedina, 2009. p. 383-417.

GROSFOGUEL, R. Para uma visão decolonial da crise civilizatória e dos paradigmas da esquerda ocidentalizada. In: BERNARDINO-COSTA, J.; MALDONADO-TORRES, N.; GROSFOGUEL, R. (org.). Decolonialidade e pensamento afrodiáspórico. Belo Horizonte: Autêntica Editora, 2018. p. 55-77. (Coleção cultura negra e identidade).

GROSFOGUEL, R. Racismo epistémico, islamofobia epistémica y ciencias sociales coloniales. Tabula Rasa, Bogotá, n. 14, v. 1, p. 341-355, 2011.

LANDER, E. et al. A colonialidade do saber: eurocentrismo e ciências sociais. Perspectivas latino-americanas. Buenos Aires: CLACSO, 2005.

MALDONADO-TORRES, N. Sobre la colonialidad del ser: contribuciones al desarrollo de un concepto. In: CASTRO-GÓMEZ, S.; GROSOFOGUEL, R. (ed.). El giro decolonial. Reflexiones para una diversidad epistémica más allá del capitalismo global. Colombia: Siglo del Hombre Editores, 2007. p. 127-167.

MATO, D. Universidades e diversidade cultural e epistémica na América Latina: experiências, conflitos e desafios. In: CANDAU, V. M. (org.). Interculturalizar, descolonizar e democratizar: uma educação "outra"? Rio de Janeiro: Fletras, 2016. p. 39-63.

MIGNOLO, W. Cartografias del poder y descolonialidad. Buenos Aires: Del Signo, 2014a.

MIGNOLO, W. (comp.). Capitalismo Y geopolítica del conocimiento: el eurocentrismo y la filosofía de la liberación en el debate intelectual contemporáneo. 2. ed. Buenos Aires: Del signo, 2014b.

MIGNOLO, W. Desobediencia epistémica: retórica de la modernidad, lógica de la colonialidad. Buenos Aires: Del signo, 2010. 
MIGNOLO, W. El vuelco de la razón: diferencia colonial y pensamiento fronterizo. Buenos Aires: Del signo, 2014c.

MIGNOLO, W. Histórias locais/projetos globais. Belo Horizonte: Editora UFMG, 2003.

MIGNOLO, W.; WALSH, C.; LINERA, Á. G. Interculturalidad, descolonización del estado y del conocimiento. Buenos Aires: Del signo, 2014.

QUIJANO, A. (ed.). Des/colonialidad y bien vivir: un nuevo debate en America Latina. Lima: Editorial Universitaria, 2014.

QUIJANO, A. Colonialidade do poder e classificação social. In: SANTOS, B. de S.; MENESES, M. P. (org.). Epistemologias do Sul. Coimbra: Almedina, 2009. p. 74-117.

SEGATO, R. L. Aníbal Quijano y la perspectiva de la colonailidad del poder. In: QUIJANO, A. (ed.). Des/colonialidad y bien vivir: un nuevo debate en América Latina. Lima: Editorial Universitaria, 2014. p. 35-71.

SOARES, Elza. Elza Soares rebate diretora da Vogue: escravizar, nem de brincadeira. TV 247, 17 fev. 2019. Disponivel em: http://amp.brasil247.com/pt/247/cultura/384171. Acesso em: 17 fev. 2019.

WALSH, C. Interculturalidade crítica e pedagogía de colonial: in-surgir, re-existir e re-vivir. In: CANDAU, V. M. F. (org.). Educação Intercultural na América Latina: entre concepções, tensões e propostas. Rio de Janeiro: 7 Letras, 2009a. p. 12-42.

WALSH, C. Interculturalidad, Estado, sociedad. Luchas (de)coloniales de nuestra época. Quito: Universidad Andina Simón Bolívar/ABYA YALA, 2009b.

WALSH, C. Interculturalidad, plurinacionalidad y decolonialidad: las insurgencias político-epistémicas de refundar el Estado. Tábula Rasa, Bogotá, n. 9, p. 131-152, jul./dic. 2008.

WALSH, C. Pedagogías decoloniales: prácticas insurgentes de resistir, (re)existir y (re)vivir. Tomo I. Quito, Ecuador: Ediciones Abya-Yala, 2013.

WALSH, C. Pedagogías decoloniales: prácticas insurgentes de resistir, (re)existir y (re)vivir. Tomo Il. Quito, Ecuador: Ediciones Abya-Yala, 2017.

WALSH, C. Interculturalidad y (de)colonialidad: diferencia y nación de otro modo. In: MAGALHÃES NETO, Hamilton (org.). Desarrollo e interculturalidad, imaginario y diferencia: la nación en el mundo andino. Río de Janeiro: Academia de la Latinidad, 2006. p. 27-43.

WALSH, C. Interculturalidad y colonialidad del poder: un pensamiento y posicionamiento "otro" desde la diferencia colonial. In: CASTRO-GÓMEZ, S.; GROSOFOGUEL, R. (ed.). El giro decolonial. Reflexiones para una diversidad epistémica más allá del capitalismo global. Colombia: Siglo del Hombre Editores, 2007. p. 47-62. 